\title{
The fraction of nitrous oxide in oxygen for facilitating lung collapse during one-lung ventilation with double lumen tube
}

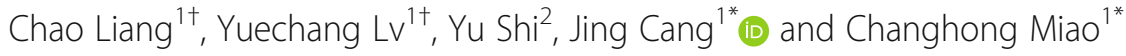

\begin{abstract}
Background: The ideal fraction of nitrous oxide $\left(\mathrm{N}_{2} \mathrm{O}\right)$ in oxygen $\left(\mathrm{O}_{2}\right)$ for rapid lung collapse remains unclear. Accordingly, this prospective trial aimed to determine the $50 \%$ effective concentration ( $E C_{50}$ ) and $95 \%$ effective concentration ( $\mathrm{EC}_{95}$ ) of $\mathrm{N}_{2} \mathrm{O}$ in $\mathrm{O}_{2}$ for rapid lung collapse.

Methods: This study included 38 consecutive patients undergoing video-assisted thoracoscopic surgery (VATS). The lung collapse score (LCS) of each patient during one-lung ventilation was evaluated by the same surgeon. The first patient received 30\% $\mathrm{N}_{2} \mathrm{O}$ in $\mathrm{O}_{2}$, and the subsequent $\mathrm{N}_{2} \mathrm{O}$ fraction in $\mathrm{O}_{2}$ was determined by the LCS of the previous patient using the Dixon up-and-down method. The testing interval was set at 10\%, and the lowest concentration was $10 \%(10,20,30,40 \%$, or $50 \%)$. The $\mathrm{EC}_{50}$ and $\mathrm{EC}_{95}$ of $\mathrm{N}_{2} \mathrm{O}$ in $\mathrm{O}_{2}$ for rapid lung collapse were analyzed using a probit test.
\end{abstract}

Results: According to the up-and-down method, the $\mathrm{N}_{2} \mathrm{O}$ fraction in $\mathrm{O}_{2}$ at which all patients exhibited successful lung collapse was 50\%. The $\mathrm{EC}_{50}$ and $\mathrm{EC}_{95}$ of $\mathrm{N}_{2} \mathrm{O}$ in $\mathrm{O}_{2}$ for rapid lung collapse were $27.7 \%$ (95\% confidence interval 19.9-35.7\%) and 48.7\% (95\% confidence interval 39.0-96.3\%), respectively.

Conclusions: In patients undergoing VATS, the $\mathrm{EC}_{50}$ and $\mathrm{EC}_{95}$ of $\mathrm{N}_{2} \mathrm{O}$ in $\mathrm{O}_{2}$ for rapid lung collapse were 27.7 and 48.7\%, respectively.

Trial registration: http://www.chictr.org/cn/ Identifier ChiCTR19 00021474, registered on 22 February 2019.

Keywords: Nitrous oxide, Lung collapse, One-lung ventilation, Double lumen

\section{Background}

Rapid lung collapse facilitates intrathoracic surgical procedures, which are particularly important for minimally invasive video-assisted thoracoscopic surgery (VATS). It is well-known that when one-lung ventilation (OLV) begins, the nonventilated lung will undergo phase I lung collapse due to elastic recoil, which usually occurs within $60 \mathrm{~s}$ [1]. When phase I lung collapse ceases, presumably

\footnotetext{
*Correspondence: cangjing1998@126.com; changhong1231988@126.com

${ }^{\dagger}$ Chao Liang and Yuechang Lv contributed equally to this work.

'Department of Anesthesia, Zhongshan Hospital, Fudan University, Shanghai, China

Full list of author information is available at the end of the article
}

due to small airway closure, the slower phase II lung collapse begins, which mainly depends on continuous gaseous diffusion or absorption atelectasis. The previously recommended measures for hastening lung collapse include carbon dioxide insufflation of the pleural space [1] and intermittent airway suction [2]. However, to our knowledge, no studies have indicated that these measures actually achieve the intended result.

The rate of gas absorption in the nonventilated lung depends on the composition of the inspired gas [3, 4]. The oxygen $\left(\mathrm{O}_{2}\right)$ fraction and solubility of any inert gas in the inspired mixture are important factors in the rate of gas absorption. If the inspired gas mixture contains a

(c) The Author(s). 2020 Open Access This article is licensed under a Creative Commons Attribution 4.0 International License, which permits use, sharing, adaptation, distribution and reproduction in any medium or format, as long as you give appropriate credit to the original author(s) and the source, provide a link to the Creative Commons licence, and indicate if changes were made. The images or other third party material in this article are included in the article's Creative Commons licence, unless indicated otherwise in a credit line to the material. If material is not included in the article's Creative Commons licence and your intended use is not permitted by statutory regulation or exceeds the permitted use, you will need to obtain permission directly from the copyright holder. To view a copy of this licence, visit http://creativecommons.org/licenses/by/4.0/. The Creative Commons Public Domain Dedication waiver (http://creativecommons.org/publicdomain/zero/1.0/) applies to the data made available in this article, unless otherwise stated in a credit line to the data. 
less soluble gas, such as nitrogen, the absorption rate is relatively slow and increases as $\mathrm{O}_{2}$ increases [4]. In contrast, when the inspired mixture contains a relatively soluble inert gas and $\mathrm{O}_{2}$, gas absorption is faster. In physiological terms, nitrous oxide $\left(\mathrm{N}_{2} \mathrm{O}\right)$ is highly soluble. In animal models $[5,6]$, it has been demonstrated that mechanical lung ventilation using an $\mathrm{O}_{2} / \mathrm{N}_{2} \mathrm{O}$ mixture will increase the rate of gaseous uptake from the non-ventilated lung and hasten its absorptive collapse. In addition, clinical studies have also indicated that, compared with an $\mathrm{O}_{2}$ /air mixture or $100 \% \mathrm{O}_{2}$, using an $\mathrm{O}_{2} / \mathrm{N}_{2} \mathrm{O}$ mixture before OLV prompts phase II lung collapse when a double-lumen endotracheal tube (DLT) or bronchial blocker (b-blocker) is used for lung isolation. Furthermore, this useful measure does not affect phase I lung collapse and cause hypoxia [7-9].

The commonly used $\mathrm{N}_{2} \mathrm{O}$ fraction in $\mathrm{O}_{2}$ for rapid lung collapse is $50 \%$ or $60 \%$ [6-8]; however, the proper fraction of $\mathrm{N}_{2} \mathrm{O}$ in $\mathrm{O}_{2}$ when this measure is used in thoracic procedures remains unclear. Accordingly, this prospective trial was designed to determine the $50 \%$ effective concentration $\left(\mathrm{EC}_{50}\right)$ and $95 \%$ effective concentration $\left(E_{95}\right)$ of $\mathrm{N}_{2} \mathrm{O}$ in $\mathrm{O}_{2}$ for rapid lung collapse.

\section{Methods}

The present study was approved by the Institutional Review Board (IRB) of Zhongshan Hospital, Fudan University (Shanghai, China; IRB:B2018-314R), and written informed consent was obtained from all subjects who participated in the trial. The trial was registered before patient enrollment at http://www.chictr.org/cn/ (ChiCTR19 00021474, Principal investigator, Chao Liang, Date of registration, February 22, 2019). Patients scheduled to undergo elective VATS for lung cancer at the Zhongshan Hospital were enrolled in the present study. All patients underwent preoperative pulmonary function tests. Patients with evidence of bullae on chest radiography, abnormal expiratory recoil (forced expiratory volume in $1 \mathrm{~s}<$ $70 \%$ of predicted value), chronic obstructive pulmonary disease or severe asthma, major medical comorbidities, or anticipated pleural adhesion were excluded.

To avoid the potential effects of inhaled volatile anesthetic on oxygenation during OLV, all patients received total intravenous anesthesia. Propofol was administered using a target-controlled infusion (TCI) device (Cardinal Health, Basingstoke, United Kingdom) based on a three-compartment population pharmacokinetic model defined by Schnider et al. [10]. Anesthesia was induced using propofol TCI (target plasma concentration set at $\left.4.0 \mu \mathrm{g} \mathrm{ml}^{-1}\right)$, remifentanil $\left(0.2 \mu \mathrm{g} \mathrm{kg}^{-1} \mathrm{~min}^{-1}\right)$, fentanyl $1 \mu \mathrm{g} \mathrm{kg}^{-1}$, and rocuronium bromide $0.6 \mathrm{mg} \mathrm{kg}^{-1}$. Anesthesia was maintained using propofol TCI (target plasma concentration set at $3.0 \mu \mathrm{g} \mathrm{ml}^{-1}$ ) infusion and intermittent boluses rocuronium. Tidal volumes were 8
$\mathrm{mL} \mathrm{kg}^{-1}$ ideal body weight during both two-lung ventilation (2LV) and OLV without positive end-expiratory pressure (PEEP). The $100 \% \mathrm{O}_{2}$ was introduced by a mask during induction for $3 \mathrm{~min}$. Patients were intubated using an appropriate-size, left-sided, DLT; the position of the DLT was confirmed using fiberoptic bronchoscopy (FOB). The selected $\mathrm{N}_{2} \mathrm{O} / \mathrm{O}_{2}$ admixture was then introduced and continued during positive pressure ventilation until the start of OLV. The patients were placed in the lateral position, and the position of the DLT was reconfirmed and adjusted using FOB as needed. At the time of skin incision, the DLT lumens were opened to the atmosphere for $60 \mathrm{~s}$, then the nonventilated lumen of the DLT was clamped for gas uptake, and OLV of the dependent lung was started with a fraction of inspired oxygen of 1.0.

\section{Measurement}

Given that all procedures were conducted using VATS, lung collapse was scored via video view. Surgeons were blinded to the gas composition, assessing LCS at $5 \mathrm{~min}$ after pleural opening using a verbal rating scale [7] scored from 0 (no lung deflation) to 10 (maximal lung collapse). FOB was used to diagnose and correct the problem when lung isolation was unsatisfactory. Baseline arterial blood gas of each patient was obtained preoperatively while patients breathed room air. After anesthesia induction, the right or left radial artery was cannulated, and blood gas samples were analyzed every $10 \mathrm{~min}$ for the first $30 \mathrm{~min}$ of OLV. The lowest $\mathrm{O}_{2}$ saturation $\left(\mathrm{SpO}_{2}\right)$ during OLV and the time required to open the lung pleura (time from start of OLV until pleural opening), end-tidal carbon dioxide, heart rate, and arterial blood pressure were also recorded. End-tidal $\mathrm{O}_{2}$ or $\mathrm{N}_{2} \mathrm{O}$ was recorded every minute from the start of OLV using an anesthetic analyzer that was a component of the anesthesia machine (IntelliVue G5, Phillips, Andover, MA, USA).

To calculate the $\mathrm{EC}_{50}$ and $\mathrm{EC}_{95}$ of $\mathrm{N}_{2} \mathrm{O}$ in $\mathrm{O}_{2}$, the $\mathrm{N}_{2} \mathrm{O}$ fraction in $\mathrm{O}_{2}$ in the first case was $30 \%$, and the subsequent $\mathrm{N}_{2} \mathrm{O}$ fraction was determined by the LCS of the previous patient using the Dixon up-and-down method. The testing interval was set at $10 \%$, and the lowest concentration of $\mathrm{N}_{2} \mathrm{O}$ was $10 \%$. "Successful lung collapse" was defined as an LCS $\geq 8$, and the $\mathrm{N}_{2} \mathrm{O}$ fraction in the subsequent patient was decreased by $10 \%$. An $\mathrm{LCS}<8$ was regarded as "fail", and the $\mathrm{N}_{2} \mathrm{O}$ fraction in the subsequent patient was increased by $10 \%$.

\section{Statistical analysis}

Statistical analysis was performed using SPSS version 19.0 (IBM Corporation, Armonk, NY, USA) and Excel 2007 (Microsoft Corporation, Redmond, WA, USA). Patient characteristics were expressed as mean and standard deviation (SD) or number. Continuous variables 
were analyzed using the t-test and categorical variables were analyzed using the chi-squared test. The mean of the mid-point of all fail/success pairs was used to calculate $\mathrm{N}_{2} \mathrm{O} \mathrm{EC}_{50}$ using up-and-down method described by Dixon and Massey, and a minimum of 8 crossover pairs were required for the analysis [11]. A dose-response curve was determined using probit analysis and interpolation was performed to obtain $\mathrm{EC}_{50}$ and $\mathrm{EC}_{95}$ with $95 \%$ corresponding confidence interval $(\mathrm{CI})$.

\section{Results}

The eligibility of 40 patients was assessed and 38 were recruited for the study (Fig. 1). All patients had satisfactory lung isolation and did not require correction of DLT malpositioning or discontinuation of OLV. An additional two patients were excluded from the study due to pneumothoracic adhesions and, consequently, difficult assessment of LCS. Ultimately, therefore, 36 patients were analyzed. The demographic characteristics of the patients are summarized in Table 1.

The $\mathrm{N}_{2} \mathrm{O}$ fraction success data of LCS for patients obtained using the up-and-down method are presented in Fig. 2. This was further analyzed by probit regression analysis. The $\mathrm{EC}_{50}$ of $\mathrm{N}_{2} \mathrm{O}$ in $\mathrm{O}_{2}$ for rapid lung collapse was $27.7 \%$ (95\% confidence interval [CI] 19.9-35.7\%). The $\mathrm{EC}_{95}$ of $\mathrm{N}_{2} \mathrm{O}$ in $\mathrm{O}_{2}$ for rapid lung collapse was 48.7\% (95\% CI 39.0-96.3\%). The $\mathrm{N}_{2} \mathrm{O}$ fraction in $\mathrm{O}_{2}$ and percentages of patients who achieved successful lung

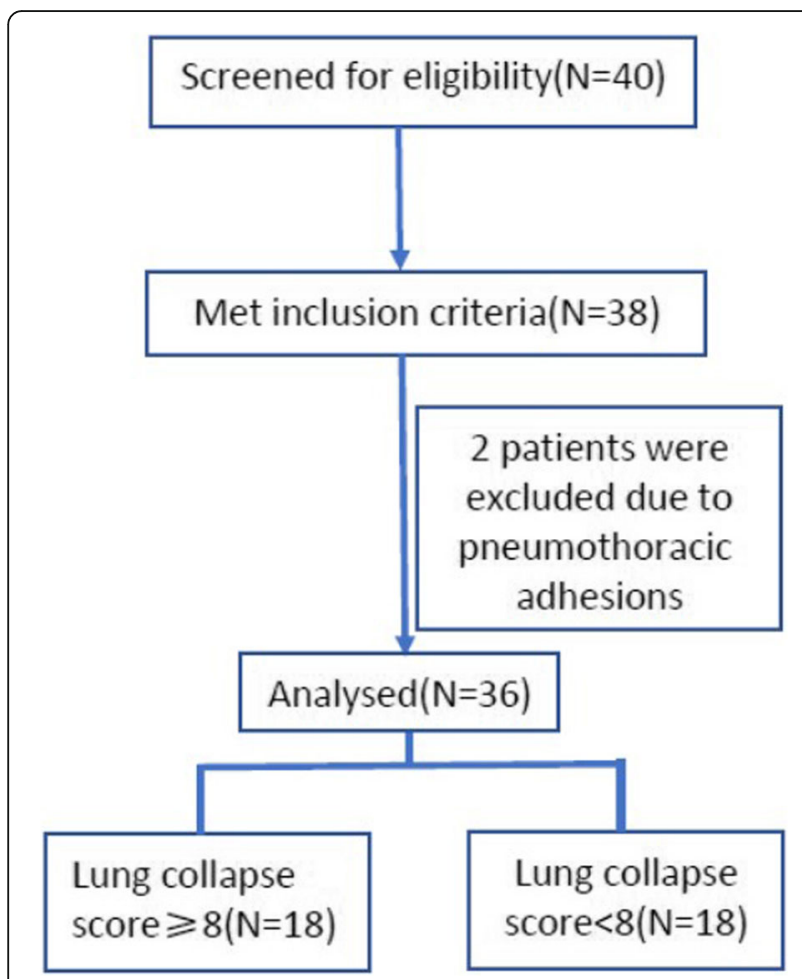

Fig. 1 Flow diagram of participants
Table 1 Demographic data of study population

\begin{tabular}{ll}
\hline American Society of & $2(1-3)$ \\
Anesthesiologists score & \\
\hline Age(y) & $52.5 \pm 9.2$ \\
Gender (male/female) & $19 / 17$ \\
Weight (kg) & $57.6 \pm 9.2$ \\
Height (cm) & $157 \pm 8.6$ \\
Smokers/Non-smokers & $3 / 33$ \\
aPleural opening(s) & $59.6 \pm 12.2$ \\
FEV1 (\% of predicted) & $84.6 \pm 12.2$ \\
FVC (\% of predicted) & $82.3 \pm 9.2$ \\
FEV1/FVC & $80.2 \pm 8.8$ \\
Surgery type & \\
VATS-R & 20 \\
VATS-L & 16 \\
\hline
\end{tabular}

FEV1 $=$ forced expiratory volume at $1 \mathrm{~s} ; \mathrm{FVC}=$ forced

vital capacity

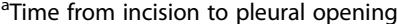

VATS = video-assisted thoracoscopic surgery

collapse (i.e., LCS $\geq 8$ ) are summarized in Table 2. The fraction-success curve of $\mathrm{N}_{2} \mathrm{O}$ plotted from probit analysis of individual $\mathrm{N}_{2} \mathrm{O}$ fractions and the respective LCS is presented in Fig. 3. Clinically significant desaturation $\left(\mathrm{SpO}_{2}<90 \%\right)$ requiring alveolar recruitment maneuvers or other interventions did not occur in any patient. During the investigation period, no other intraoperative hemodynamic events (hypotension, tachycardia, and bradycardia) were recorded or required intervention.

\section{Discussion}

The use of an $\mathrm{N}_{2} \mathrm{O} / \mathrm{O}_{2}$ mixture is a useful method for rapid lung collapse. The present study determined that the $\mathrm{EC}_{50}$ of $\mathrm{N}_{2} \mathrm{O}$ in $\mathrm{O}_{2}$ for rapid lung collapse was $27.7 \%$.

The underlying mechanism of an $\mathrm{N}_{2} \mathrm{O} / \mathrm{O}_{2}$ inspired gas mixture leads to rapid lung collapse may attributed to a "second gas" effect, which is the rapid absorption of $\mathrm{N}_{2} \mathrm{O}$ facilitating $\mathrm{O}_{2}$ uptake, or to a concentration effect, or to gas solubility [12]. During OLV, the nonventilated lung collapses initially due to elastic recoil, and the remaining gas is then removed by absorption into the pulmonary capillary blood [6]. Thus, in the present study, for complete lung collapse by elastic recoil, both nonventilated and ventilated lumens of the DLT were opened to the atmosphere for $60 \mathrm{~s}$, then the nonventilated lumen was clamped for gas uptake. The average time of plural opening in the present study was approximately $60 \mathrm{~s}$ (mean, $59.6 \pm 12.2 \mathrm{~s}$ ), which is consistent with previous studies reporting on plural opening in VATS [7]. Then, a verbal rating scale [7, 8], scored from 0 (no lung deflation) to 10 (maximal lung collapse), was used by the surgeon to score the patient's lung collapse condition. Other studies $[13,14]$ have also used a four- 


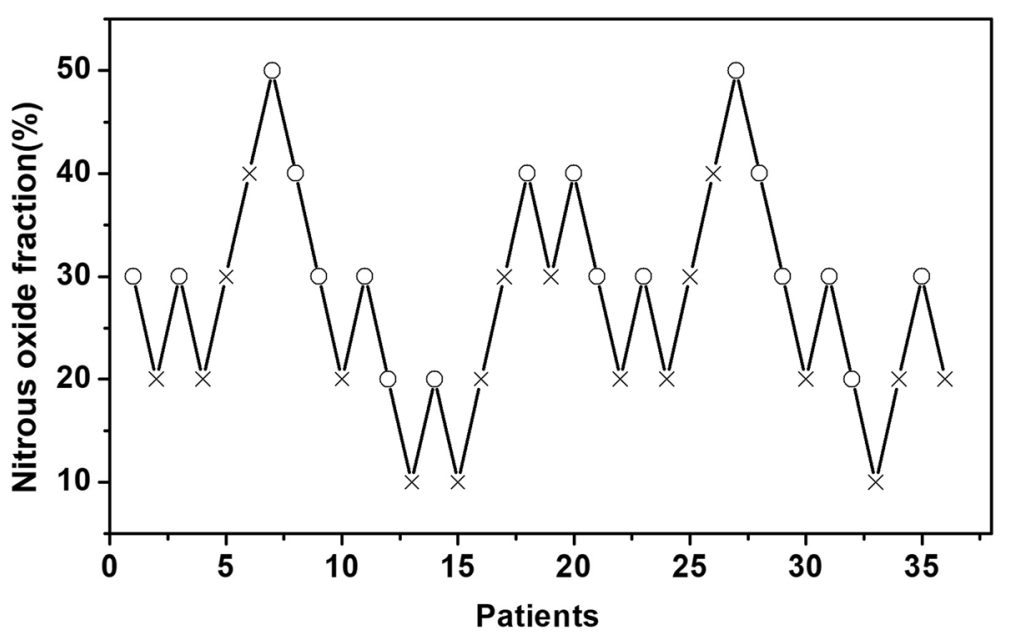

Fig. 2 The sequential lung collapse score of 36 patients to nitrous oxide with the up-and-down method. $x=$ lung collapse score $<8$; $0=$ lung collapse score $\geq 8$

point ordinal scale (1, extremely poor to no collapse of the lung; 2, poor partial collapse with interference with surgical exposure; 3 , good total collapse, but the lung still contained residual air; and 4, excellent to complete collapse with perfect surgical exposure). To evaluate the condition of the lung, however, defining a "success" and "fail" condition is a necessary step for determining $\mathrm{EC}_{50}$ using the up-and-down method. Compared with a fourpoint ordinal scale, a verbal rating scale from 0 to 10 appears to be more accurate for scoring lung collapse condition. Moreover, in our pilot study, virtually all surgeons regarded LCS $\geq 8$ as a proper condition for lung manipulations; thus, we defined LCS $\geq 8$ as "success" and $<8$ as "fail".

In a study investigating the use of a b-blocker as a lung isolation tool, the LCS of $50 \% \mathrm{~N}_{2} \mathrm{O}$ in $\mathrm{O}_{2}$ was significantly higher compared with that of $100 \% \mathrm{O}_{2}$ at $5 \mathrm{~min}$ after opening the pleura; however, $<50 \%$ patients' LCS was $\geq 8$ [7]. In another study, in which DLT was used as the lung isolation tool, when $50 \% \mathrm{~N}_{2} \mathrm{O}$ was applied, the average LCS was 9 at 10 min after opening the pleura, although the investigators did not report LCS at $5 \mathrm{~min}$ after opening the pleura [8]. When $30 \% \mathrm{~N}_{2} \mathrm{O}$ in $\mathrm{O}_{2}$ was used in our pilot study, approximately $50 \%$ of patients

Table 2 Percentages of patients who had successful lung collapse score (lung collapse score equal to or more than 8).

\begin{tabular}{ll}
\hline Nitrous oxide fraction in each subgroup (\%) & Success rate \\
\hline 10 & $0 \%(0 / 3)$ \\
20 & $25 \%(3 / 12)$ \\
30 & $68 \%(9 / 13)$ \\
40 & $67 \%(4 / 6)$ \\
50 & $100 \%(2 / 2)$ \\
\hline
\end{tabular}

had an LCS $\geq 8$. Differences in LCS 5 min after opening the pleura between our study and the study investigating b-blockers as the lung isolation tool may largely be attributed to the different isolation tools and the surgeon's personal LCS scoring criteria.

In previous studies $[7,8]$, the target gas mixtures of $\mathrm{N}_{2} \mathrm{O}$ and $\mathrm{O}_{2}$ were used at the time of preoxygenation during anesthesia induction, and the gas concentrations before OLV were equal to the target concentrations. In the present study, $100 \% \mathrm{O}_{2}$ was used for preoxygenation, and the selected $\mathrm{N}_{2} \mathrm{O}$ and $\mathrm{O}_{2}$ gas mixtures were then used after intubation. However, before OLV, all selected $\mathrm{N}_{2} \mathrm{O}$ and $\mathrm{O}_{2}$ gas mixtures were equal to the target

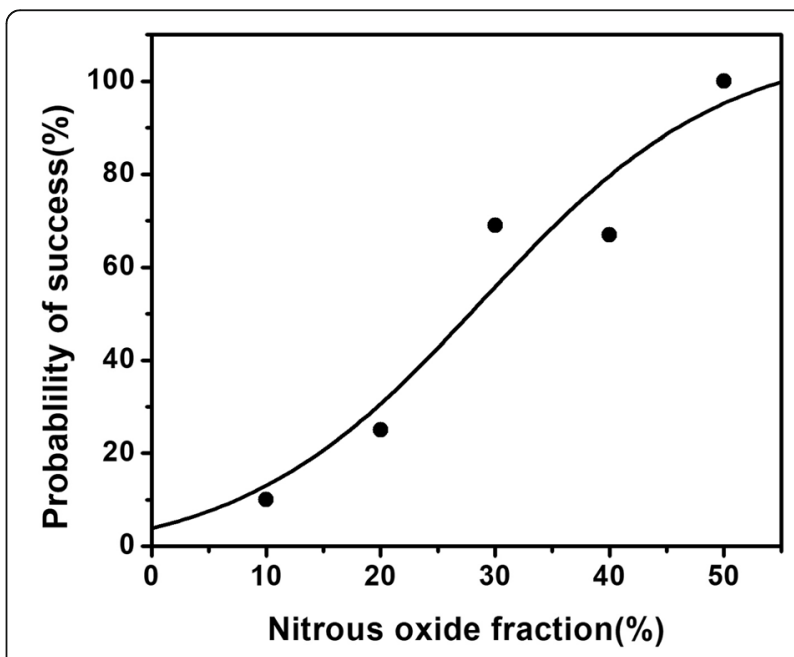

Fig. 3 Dose-response curve for nitrous oxide plotted using probit analysis. The $50 \%$ effective concentration was $27.7 \%$ (95\% confidence interval, 19.9-35.7\%). The 95\% effective concentration was $48.7 \%$ (95\% confidence interval, 39.0-96.3\%) 
mixtures. Therefore, it appears that using $\mathrm{O}_{2}$ for induction, and switching to $\mathrm{N}_{2} \mathrm{O}$ and $\mathrm{O}_{2}$ after intubation is more applicable because a "more $\mathrm{O}_{2}$ induction period" is safer than one that involves less. Regarding operation type, all patients in the present study underwent VATS for lung surgery, which is the primary surgery type for lung tumors, and the enrolled cases in previous studies mainly underwent open thoracotomies. Compared with open thoracotomies, the lung collapse condition is more important for VATS; thus, data from the present study are more applicable to modern clinical practice(s).

The present study had several limitations. First, for the purposes of this study, we determined the success or failure of lung collapse based on the surgeons' scoring scale, which was not entirely objective. However, similar to the methods used in previous studies, using more objective criteria, such as the distance of the collapsed lung to the chest wall, appears to be less clinically relevant due to varying sizes of patient chests. Therefore, the most clinically relevant assessment of the lung collapse condition is the surgeon's opinion. Second, the tidal volumes were $8 \mathrm{~mL} \mathrm{~kg}^{-1}$ ideal body weight during both 2LV and OLV without PEEP. However, this has been associated with increased postoperative complications and mortality [15]. Furthermore, an adequate amount of PEEP was shown to be effective in reducing stress to the dependent lung and V/Q mismatch [16]. Applying PEEP to the dependent lung should also influence the primary outcome. In fact, LCS was assessed by a surgeon who could have been confounded by a more inflated dependent lung. Third, all patients in the present study demonstrated relatively normal results on pulmonary function testing (including 3 smokers) and body mass indices. As such, the results of our study may not be applicable to patients with poor pulmonary function test results, or to obese patients and/or smokers. Lastly, the duration of administration of the $\mathrm{O}_{2} / \mathrm{N}_{2} \mathrm{O}$ admixture was from the confirmation of DLT with FOB to the time of skin incision, and unfortunately, we did not record the time of this period. These concerns may be addressed in future studies.

\section{Conclusion}

When a DLT was used for lung isolation in patients undergoing VATS, the $\mathrm{EC}_{50}$ and $\mathrm{EC}_{95}$ of $\mathrm{N}_{2} \mathrm{O}$ in $\mathrm{O}_{2}$ during $2 \mathrm{LV}$ for accelerating lung collapse during OLV were 27.7 and $48.7 \%$, respectively.

\section{Abbreviations}

$\mathrm{N}_{2} \mathrm{O}$ : Nitrous oxide; $\mathrm{O}_{2}$ : Oxygen; $\mathrm{EC}_{50}$ : 50\% effective concentration; $\mathrm{EC}_{95}: 95 \%$ effective concentration; VATS: Video-assisted thoracoscopic surgery; LCS: Lung collapse score; OLV: One-lung ventilation; DLT: Double-lumen tube; b-blocker: Bronchial blocker; $\mathrm{FEV}_{1}$ : Forced expiratory volume at $1 \mathrm{~s}$; TCl: Target-controlled infusion; FOB: Fiberoptic bronchoscopy; Cl: Confidence intervals

\section{Acknowledgements}

Not applicable.

\section{Authors' contributions}

$Y C L$ and $C L$ conceived and designed the study, collecting and interpretation of data, and drafting the manuscript. YS carried out the statistical analysis, and was involved in interpretation of data and drafting the manuscript. CJ and ZG X was involved in designing the study, and was involved in interpretation of data and drafting the manuscript. All of the authors critically revised and approved the final form of the manuscript.

\section{Funding}

This work was supported by the Natural Science Foundation of China (Grant no. 81400930).

\section{Availability of data and materials}

Reasonable requests for access to the datasets used and/or analysed during this study can be made to the corresponding author.

\section{Ethics approval and consent to participate}

This study was approved (IRB: B2018-314R) by the Ethics Committee of Zhongshan Hospital, Fudan University on Dec 4, 2018. All of the participants gave their written, informed consent to participate in the study.

\section{Consent for publication}

Not applicable.

\section{Competing interests}

The authors declare that they have no competing interests.

\section{Author details}

'Department of Anesthesia, Zhongshan Hospital, Fudan University, Shanghai, China. ${ }^{2}$ Department of Thoracic surgery, Zhongshan Hospital, Fudan University, Shanghai, China.

Received: 26 February 2020 Accepted: 16 July 2020

Published online: 22 July 2020

\section{References}

1. Landreneau RJ, Mack MJ, Hazelrigg SR, Dowling RD, Acuff TE, Magee MJ, Ferson PF. Video-assisted thoracic surgery: basic technical concepts and intercostal approach strategies. Ann Thorac Surg. 1992;54(4):800-7.

2. Baraka A. Hazards of carbon dioxide insufflation during thoracoscopy. $\mathrm{Br} J$ Anaesth. 1998;81(1):100.

3. Dale WA, Rahn H. Rate of gas absorption during atelectasis. Am J Phys. 1952;170(3):606-13.

4. Joyce $C J$, Baker $A B$, Kennedy RR: Gas uptake from an unventilated area of lung: computer model of absorption atelectasis. J Appl Physiol (1985) 1993, 74(3):1107-1116.

5. Joyce $C J$, Baker AB, Parkinson R, Zacharias M. Nitrous oxide and the rate of gas uptake from an unventilated lung in dogs. Br J Anaesth. 1996;76(2):292-6.

6. Pfitzner J, Peacock MJ, Pfitzner L. Speed of collapse of the non-ventilated lung during one-lung anaesthesia: the effects of the use of nitrous oxide in sheep. Anaesthesia. 2001;56(10):933-9.

7. Yoshimura T, Ueda K, Kakinuma A, Sawai J, Nakata Y. Bronchial blocker lung collapse technique: nitrous oxide for facilitating lung collapse during onelung ventilation with a bronchial blocker. Anesth Analg. 2014;118(3):666-70.

8. Ko R, McRae K, Darling G, Waddell TK, McGlade D, Cheung K, Katz J, Slinger P. The use of air in the inspired gas mixture during two-lung ventilation delays lung collapse during one-lung ventilation. Anesth Analg. 2009;108(4):1092-6.

9. Joyce $C J$, Baker $A B$. What is the role of absorption atelectasis in the genesis of perioperative pulmonary collapse? Anaesth Intensive Care. 1995;23(6):691-6.

10. Schnider TW, Minto CF, Gambus PL, Andresen C, Goodale DB, Shafer SL, Youngs EJ. The influence of method of administration and covariates on the pharmacokinetics of propofol in adult volunteers. Anesthesiology. 1998; 88(5):1170-82.

11. Dixon WJ. Staircase bioassay: the up-and-down method. Neurosci Biobehav Rev. 1991;15(1):47-50.

12. Pfitzner J, Peacock MJ, Harris RJ. Speed of collapse of the non-ventilated lung during single-lung ventilation for thoracoscopic surgery: the effect of 
transient increases in pleural pressure on the venting of gas from the nonventilated lung. Anaesthesia. 2001;56(10):940-6.

13. El-Tahan MR. A comparison of the disconnection technique with continuous bronchial suction for lung deflation when using the Arndt endobronchial blocker during video-assisted thoracoscopy: a randomised trial. Eur J Anaesthesiol. 2015;32(6):411-7.

14. Li Q, Zhang X, Wu J, Xu M. Two-minute disconnection technique with a double-lumen tube to speed the collapse of the non-ventilated lung for onelung ventilation in thoracoscopic surgery. BMC Anesthesiol. 2017;17(1):80

15. Blank RS, Colquhoun DA, Durieux ME, Kozower BD, McMurry TL, Bender SP, Naik Bl. Management of one-lung Ventilation: impact of tidal volume on complications after thoracic surgery. Anesthesiology. 2016;124(6):1286-95.

16. Spadaro S, Grasso S, Karbing DS, Fogagnolo A, Contoli M, Bollini G, Ragazzi R, Cinnella G, Verri M, Cavallesco NG, et al. Physiologic evaluation of ventilation perfusion mismatch and respiratory mechanics at different positive end-expiratory pressure in patients undergoing protective one-lung ventilation. Anesthesiology. 2018;128(3):531-8.

\section{Publisher's Note}

Springer Nature remains neutral with regard to jurisdictional claims in published maps and institutional affiliations.

Ready to submit your research? Choose BMC and benefit from:

- fast, convenient online submission

- thorough peer review by experienced researchers in your field

- rapid publication on acceptance

- support for research data, including large and complex data types

- gold Open Access which fosters wider collaboration and increased citations

- maximum visibility for your research: over $100 \mathrm{M}$ website views per year

At $\mathrm{BMC}$, research is always in progress.

Learn more biomedcentral.com/submissions 